\title{
Rudi Matthee. "Infidel Aggression: The Russian Assault on the Holy Shrine of Imam Reza, Mashhad, $1912 "$
}

\section{Alisa Shablovskaia}

\section{(2) OpenEdition Journals}

Édition électronique

URL : http://journals.openedition.org/abstractairanica/50343

DOI : 10.4000/abstractairanica. 50343

ISBN : 1961-960X

ISSN : 1961-960X

Éditeur :

CNRS (UMR 7528 Mondes iraniens et indiens), Éditions de l'IFRI

\section{Référence électronique}

Alisa Shablovskaia, «Rudi Matthee. "Infidel Aggression: The Russian Assault on the Holy Shrine of Imam Reza, Mashhad, 1912" », Abstracta Iranica [En ligne], Volume 40-41 | 2019, document 6, mis en ligne le 30 décembre 2019, consulté le 22 avril 2021. URL : http://journals.openedition.org/ abstractairanica/50343 ; DOI : https://doi.org/10.4000/abstractairanica.50343

Ce document a été généré automatiquement le 22 avril 2021.

Tous droits réservés 


\title{
Rudi Matthee. "Infidel Aggression: The Russian Assault on the Holy Shrine of Imam Reza, Mashhad, $1912 "$
}

\author{
Alisa Shablovskaia
}

\section{RÉFÉRENCE}

Rudi Matthee. "Infidel Aggression: The Russian Assault on the Holy Shrine of Imam Reza, Mashhad, 1912" in Rudi Matthee, Elena Andreeva (eds.). Russians in Iran: diplomacy and power in the Qajar era and beyond. London : I.B. Tauris \& Co. LTD, 2018, p. 136-172

1 La contribution de Matthee représente le chaînon manquant d'une historiographie plus vaste du mouvement constitutionnel iranien. Cet article décrit les circonstances de l'intervention militaire russe dans le Khorasan en 1912, qui eut lieu suite à la radicalisation des partisans de l'ex-chah Muhammad 'Ali après l'échec de sa campagne de retour et la dispersion du parlement iranien sous la pression diplomatique russe en décembre 1911. En confrontant les sources russes, anglaises et iraniennes, l'auteur reconstitue les événements accompagnant le bombardement du sanctuaire Imam Reza à Machhad (30 mars 1912) - le lieu de refuge des insurgés - et met en exergue la subjectivité ambiguë des documents britanniques issus de la correspondance du consul Sir Percy Sykes. L'article démontre comment l'enchevêtrement des stratégies consulaires russes et britanniques avec les intérêts des acteurs locaux iraniens se solda par l'autonomisation de ces derniers, conduisant au dénouement tragique de la révolte à Machhad. Tout en restant critique vis-à-vis des sources russes et admettant la probabilité d'une conspiration orchestrée par le consulat tsariste, l'auteur construit son argumentation autour de trois thèses : 1) il existe assez d'évidences pour confirmer la non-complicité entre le consulat à Machhad et le gouvernement à Saint-Pétersbourg ; 2) au stade initial de la révolte, il existait un accord entre le consulat russe et les 
insurgés ; 3) le consul anglais était impliqué dans la lutte politique qui se déroulait à Machhad autant que son homologue russe. Cependant, la complicité entre le consulat britannique et les insurgés, stipulée dans les sources russes, ne fait pas l'objet d'analyse dans l'article ce qui laisse le lecteur perplexe et avide d'informations supplémentaires.

\section{AUTEURS}

\section{ALISA SHABLOVSKAIA}

Doctorante Sorbonne Nouvelle, Mondes iranien et indien, Paris 